\title{
Voice Activated Virtual Assistants Personality Perceptions and Desires: Comparing Personality Evaluation Frameworks
}

\author{
Dr Marta Perez Garcia \\ Telefonica R\&D \\ Madrid, Spain \\ Marta.perezgarcia@telefonica.com \\ Sarita Saffon Lopez \\ Telefonica R\&D \\ Madrid, Spain \\ Sarita.saffonlopez@telefonica.com
}

\author{
Hector Donis \\ Telefonica Digital \\ Madrid, Spain \\ Hector.Donis@telefonica.com
}

\begin{abstract}
Currently, Voice Activated Virtual Assistants and Artificial Intelligence technologies are not just about performance or the functionalities they can carry out, it is also about the associated personality. This empirical multi-country study explores the personality perceptions of current VAVA users regarding these technologies. Since this is a rather unexplored territory for research, this study has identified two well-established personality evaluation methodologies, Aaker's traits approach and Jung's archetypes, to investigate current perceived personality and future desired personality of the four main Voice Activated Virtual Assistants: Siri, Google Assistant, Cortana and Alexa. Following are a summary of results by each methodology, and an analysis of the commonalities found between the two methodologies.
\end{abstract}

Personality, Artificial Intelligence, Voice Activated Virtual Assistant.

\section{INTRODUCTION}

In 2000, Microsoft researchers Gene Ball and Jack Breeze wrote that "in twenty years (possibly much sooner)" humans would interact with computers via spoken conversation. As predicted, that moment has come already, much before than the year 2020. Actually, voice is now considered by experts as the key shift in humanmachine interaction (Eadiciccio, 2017), and as Ball and Breeze (2000) note as well, it could become the preferred means to communicate with technological devices.

Following this evolution, a vast amount of technological companies have been developing artificial intelligence (Al) that are activated and interacted with by voice. Therefore, it seems assured that the technological challenges that Ball and Breeze (2000) reported as a barrier to get to this point, have been overcome.

However, there is a new common concern these technologies face: Al's personality. This subject requires to take into account not only the technological aspects but to be able to create a pleasant interaction that generates engagement with the users, so that they actually want to interact with the device, making a special focus on the user experience (UX) (McKay, 2017).
The personality the Al will project represents a key aspect that influences the effect that an Al interface, such as voice, will generate on the user. Leif Haven Martinson, lead designer of Botanic Technologies, highlights this importance at the Stanford University's Creating Al Conversations Panel Series (2018). He claims that personality is in itself the UX of Al, because Al not only broadcast information to users, it interacts with them; therefore, personality certifies that the value of the experience is received by them.

The main challenge in Al personality is to develop a character that is able to simulate the most effective human interlocutors: They must be natural and believable, but moreover, they must convey personality, mood, and expression (Mairesse and Walker, 2007). The importance of building an Al personality is a key aspect for generating trust in technologies such as Voice Activated Virtual Assistants (Perez and Saffon, 2018).

The objective of this study is to evaluate people's perceptions around personality under two different personality evaluation frameworks to help determine their suitability in Al products, more precisely in Voice Activated Virtual Assistants. It will also look at analysing the results obtained separately and then commonly to identify if they demonstrate convergent findings. 


\section{PERSONALITY FOR AI AND VAVAS}

The definition of the term personality is not only varied, but also debated (Mayer, 2007). However, David Funder (2001) provides a definition that neither includes nor excludes humans, animals, robots or others from the possibility of having one, allowing to use the definition to approach the development of an Al personality. Funder expresses that personality "refers to an individual's characteristic patterns of thought, emotions, and behavior, together with the psychological mechanisms -hidden or not- behind those patterns" (p.2).

Before Funder's definition of personality, Dave Moffat remarked in 1997 that personality had not been "a serious topic in Al ... [because] it is not easy to explain why a robot should need a personality". Nevertheless, as the same author states, further research has shown that psychological attributes in Al have an effect in the user experience and the resulting user satisfaction with the conversational agent. An Al personality improves the system performance (Reilly, 1996) and provides quality to the experience (Johnson, 2017). Additionally, Dr. Matashi Mori (1970) states that as an Al becomes more human-like there is an increase in the levels of acceptability and affinity with the device, and that giving the Al a personality is a step towards creating a more human-like dialogue and creates a more naturalistic conversation ( $\mathrm{Li}$ et al., 2016). The development of a personality, then, influences the generation of trust, which has been shown to be an essential factor in the development and adoption of Al systems (Perez and Saffon, 2018).

As Short (2017) also describes, even though users are wise enough to know that behind the Al there are code and algorithms, they like to believe that it has real needs and desires. Furthermore, Cohen et al. (2004) state that as human beings we are unable to prevent ourselves from deducing personality attributes from a voice, regardless of its origin, even if it is a recording. A mental image is created with personal traits, attitudes, background information and even physical characteristics. This group of elements inferred by the user around the Al's language and voice is known as persona ( $\mathrm{Li}$ et al., 2016). It is described as the constant character that the user attributes to the voice, a continual line that runs underneath the surface, even regardless of changes in the tone of voice (Stanford University, 2018).

In this study, personality will refer to Funder's (2001) definition, which is based on a series of thought patterns rather than a wide range of attributes that might even include physical image (Li et al., 2016).
When developing a Voice Activated Virtual Assistant (VAVA) personality, there is a crucial challenge to be considered: How to transmit both affective and personalized qualities in the form of a consistent and realistic speech when embedded in a computational framework (Neff et al., 2010) that needs to adapt itself to the different types of interaction users might use (Li et al. 2016).

\subsection{Measuring personality}

The assessment of personality is credited to the field of psychology and can be dated back to the First World War. Psychologist Robert Woodworth developed the Personal Data Sheet in order to identify fragile draftees, assessment that was later on improved by Robert Bernreuter in 1931. This resulted in the most used basis for personality inventories, which have been applied to the Minnesota Multiphasic Personality Inventory (MMPI), Personality Assessment Inventory (PAI), and the NEO Personality Inventory (NEO-PI) (Weigner and Greene, 2017).

More than 60 years later, various marketers such as Joseph Plummer (1985) and Jeffrey Durgee (1988) started arguing that brands, as humans, had personality. Taking the latter premise into account, social psychologist Jennifer Aaker developed a model based on attributing human traits, such as honest, technical, reliable, cheerful, intelligent, and so on to a brand (Aaker, 1997) in order to determine its personality.

Aaker's model is nowadays one of the most wellestablished brand personality assessment methodology in marketing and branding research (Schlesinger and Cervera, 2009) as she defines brand personality as a "set of human characteristics associated with a brand" (Aaker, 1997). Moreover, different studies have run with the purpose of validating and adjusting personality characteristics to the context, regarding both cultural and brand category (Barrios and Massa, 1999; Koebel and Ladwein, 1999; Aaker et al., 2001; Supphellen and Grohaug, 2003; Olvarrieta et al., 2010). Many researchers have therefore explored using Aaker's methodology diverse groups of brands or even tourism destinations' personalities (Ekinci and Hosany, 2006), but none of them have tried the traits-approach to measure a VAVA personality.

More recently, another personality model based on Carl Jung's archetypical theory (Jung, 1954) has been used to assess brand personality by both brand research (Robert, 2010; Bechter et al., 2016) and brand practitioners, such as the communication giant WPP Group (Klarquist, 2010). For Jung, the Swiss psychiatrist, archetypes were intrinsic images that repeat themselves along cultures and generations, and are able to mold 
human experiences (Jung, 1954). Currently, his theory "provides a sound, proven methodology for stablishing a memorable and compelling brand identity, one that can withstand the test of time, cross lifestyle and cultural boundaries" (Mark and Pearson, 2001, p.18).

The names, quantity and description of the archetypes varies along the literature (Jansen, 2006; Woodside et al., 2008; Roberts, 2010), but are based essentially in the same original Jungian theory. Mark and Pearson (2001) developed a twelve archetypes framework now widely used for brand personality assessment (Faber and Mayer, 2009; Munteanu et al., 2010; Bolhuis, 2011; Hoolwerff, 2014) and presented in Table 1.

Table 1: Personality Archetypes

\begin{tabular}{|c|c|c|}
\hline Creator & Innocent & Ruler \\
\hline Jester & Caregiver & Hero \\
\hline Lover & Sage & Outlaw \\
\hline Every Man & Wizard & Explorer \\
\hline
\end{tabular}

Even though both Aaker's traits and Jung's archetypes have been used in various frameworks in order to measure brand personality, in the literature just Bechter et al. (2016) have explored the link between them in the advertising context, where they found that there is common ground between the two approaches.

\section{CONTEXT OF THIS RESEARCH STUDY}

This study is undertaken in Telefonica, a multinational telecoms organization based in Spain but present in more than twenty countries. The reason behind it is that Telefonica has been developing its own Al, or more specifically a Voice Activated Virtual Assistant (VAVA), called Aura, which is currently available in six countries of its footprint: Chile, Argentina, Brazil, UK, Germany and Spain. Consequently, as with many other technology players already seen in the literature, the next step is not only focused on technology capabilities but on creating a personality that is embedded and able to transmit the desired user experience. Aura's team has set a new objective: bring Aura's personality to life.

The main goal of this study was to explore what is the personality attributed by users to the four key VAVAs currently in the market (Siri, Google, Cortana and Alexa) as well as to identify what is their desired VAVA personality in the future. This would provide the team with a competitors' personality benchmark and a possible guideline into what territory could Aura's personality play in and how it could differentiate itself from others. Due to the size of the sample, it would be possible to discover variances by country and by VAVA to explore cultural and experiential differences.

\section{METHODOLOGY AND SAMPLE}

To explore personality perceptions and desires of current VAVA's users, a quantitative study was carried out with an online survey. The sample was comprised of a total of 3661 internet users, between 18 and 65 years old, in six different countries (Argentina, Brazil, Chile, Spain, Germany and UK) who used, at least, one of the main four VAVAs: Siri, Cortana, Google or Alexa. In the case they used several, they were asked about the one they used most frequently.

Based on the literature review, two brand personality assessment were chosen for the measurement of the VAVA personality: Aaker's and Jung's. The reason for this is the universality of Jung archetypes and the multiples studies made around the world in order to adapt Aaker personality-traits approach, which fitted best a multi-country study. Secondly, the Als to be evaluated are conversational agents with no physical presence (Stanford University, 2018), and they are all associated to a brand (Alexa to Amazon, Siri to Apple, Cortana to Microsoft and Google Assistant to Google). Consequently, human traits linked to the brands could also be associated with the VAVAs. In this study, Aaker personality traits (1997) and Jung's archetypes (1954), were explored by two different group of users in the six countries of the study in relationship to the four VAVAs.

The reason to use these two different methodologies instead of only one was to be able to articulate a cross-methodology analysis of results. Both approaches are well established in literature but for the robustness of this exploratory study we wanted to test if users' choice of isolated attributes would match with the selected archetypes as these seem to have a more complex set of connotations and context associated to them. The objective was, therefore, to enable the team to validate more strongly the results acquired.

Personality evaluation methodology 1 , based on Aaker's personality traits (1997), was applied to 3037 users. The construction of the attributes list was done through a methodology used in brand personality related research (Ekinci and Riley, 2003; Pirela et al., 2004; Sung and Tinkham, 2005; First and Grbac, 2007; Schlesinger and Cervera, 2009), in order achieve a number of attributes that did not generate respondents fatigue and that were the most relevant traits for the category being assed. From a list of 60 characteristics based on Aaker's 42 traits (1997) and on various adaptations mentioned in the literature review (Aaker et al., 2001; Schlesinger and Cervera, 2009; Olvarrieta et al., 2010; Bechter et al., 2016), an internal research team in Telefonica chose the 29 most relevant traits to the VAVAs context (Table 2). 
Table 2: Personality traits in survey to be attributed to current and desired VAVA personality

\begin{tabular}{|c|c|c|}
\hline Practical & Well-Mannered & Imaginative \\
\hline Informed & Thoughtful & Considerate \\
\hline Original & Helpful & Rugged \\
\hline Intelligent & Friendly & Fun \\
\hline Up-to-date & Kind & Feminine \\
\hline Logical & Sincere & Cheerful \\
\hline Technical & Genuine & Masculine \\
\hline Objective & Reliable & Sentimental \\
\hline Rational & Self-Confident & Sweet \\
\hline Honest & Nice & \\
\hline
\end{tabular}

In this methodology, respondents would choose what attributes (as many as they wanted) out of the 29 presented characterize their current VAVA. The five attributes with a higher percentage of choice were selected to define the personality of their current VAVA. Participants also had to choose attributes for their desired VAVA and from those chosen they then selected three that were indispensable. The five attributes with a higher percentage that participants have selected as indispensable for their future VAVA, were selected as the key desired personality attributes.

Personality evaluation methodology 2 , based on Carl Jung's archetypes (1954), was applied to the remaining 624 participants. The archetype selection process was based on Betcher et al (2016) and the Pearson-Marr Archetype Indicator (Pearson and Marr, 2002). The description of each archetype was constructed by the team taking reference from various sources (Mark and Pearson, 2001; Faber and Mayer, 2009; Munteanu et al., 2010; Roberts, 2010), and are presented in Table 3. Nevertheless, archetypes names were not shown to the participants so they could only focus on the description with no label associated. Participants were presented the 12 personality archetypes in the form of a description (Table 3) and were asked to discard the six that would least represent the personality of their current VAVA. Secondly, they were asked to discard three more archetypes to finally rank the three descriptions remaining. Within these, they had to choose the one that most resembled their current VAVA personality. The same process was done for their desired VAVA personality.

In both methodologies, randomization of attributes and archetypes was used in order to avoid bias when choosing due to the same order.
Table 3: Archetypes descriptions offered on survey to be attributed to current and desired VAVA personality

\begin{tabular}{|c|c|}
\hline EXPLORER & OUTLAW \\
\hline $\begin{array}{l}\text { Likes to try new things, } \\
\text { constantly looking for } \\
\text { something better. With } \\
\text { an independent and } \\
\text { curious mind, wants to } \\
\text { experience a satisfying } \\
\text { and authentic life. } \\
\text { and }\end{array}$ & $\begin{array}{l}\text { Disruptive force that } \\
\text { violates rules and } \\
\text { norms for the good of } \\
\text { others, adventure or its } \\
\text { own good. }\end{array}$ \\
\hline LOVER & WIZARD \\
\hline $\begin{array}{l}\text { It has the ability of love, } \\
\text { romance, and loyalty } \\
\text { for the other. Its } \\
\text { ambition is to have a } \\
\text { relationship with } \\
\text { people, work and the } \\
\text { experiences that it } \\
\text { loves. }\end{array}$ & $\begin{array}{l}\text { Ability to change or } \\
\text { transform } \\
\text { circumstances by } \\
\text { understanding the } \\
\text { fundamental laws and } \\
\text { applying them to make } \\
\text { things happen. }\end{array}$ \\
\hline JESTER & CAREGIVER \\
\hline $\begin{array}{l}\text { Characterized by the } \\
\text { joy when working and } \\
\text { living, it teaches us to } \\
\text { relax, to live the } \\
\text { moment and to enjoy } \\
\text { others without thinking } \\
\text { about what others } \\
\text { think. Innovative } \\
\text { thinking and out of the } \\
\text { ordinary. }\end{array}$ & $\begin{array}{l}\text { Concerned about } \\
\text { helping others, } \\
\text { motivated by } \\
\text { compassion and } \\
\text { generosity, anticipating } \\
\text { the needs of others, } \\
\text { seeing what will make } \\
\text { them feel more secure } \\
\text { and protected. }\end{array}$ \\
\hline $\mathrm{HEI}$ & INNOCENT \\
\hline $\begin{array}{r}\text { Characteri } \\
\text { competiti } \\
\text { seeks to be } \\
\text { improve the } \\
\text { prote }\end{array}$ & $\begin{array}{c}\text { Evokes self-confidence } \\
\text { and in others, seeking } \\
\text { to make life simpler and } \\
\text { reach happiness. }\end{array}$ \\
\hline SAGE & EVERYMAN \\
\hline $\begin{array}{c}\text { Uses intelligence, } \\
\text { analysis and critical } \\
\text { thinking to understand } \\
\text { the world, give opinions } \\
\text { and make informed } \\
\text { decisions. }\end{array}$ & $\begin{array}{l}\text { Its underlying value is } \\
\text { that everyone is } \\
\text { important the way they } \\
\text { are, have a value and } \\
\text { are part of a group. Its } \\
\text { goal is to belong. }\end{array}$ \\
\hline CREA & RULER \\
\hline $\begin{array}{l}\text { Innovative spirit that } \\
\text { has unique ability to } \\
\text { imagine things in a } \\
\text { different way through } \\
\text { imagination and mental } \\
\text { agility. }\end{array}$ & $\begin{array}{c}\text { Take control of } \\
\text { situations, especially } \\
\text { when they seem to be } \\
\text { getting out of control. } \\
\text { Its job is to take } \\
\text { responsibility for } \\
\text { making life as } \\
\text { predictable and stable } \\
\text { as possible. }\end{array}$ \\
\hline
\end{tabular}

\section{FINDINGS}

This empirical study has shed light onto various topics regarding the personality users perceive from their current VAVAs and what they would like it to be in the future. Moreover, differences between each of the VAVA's are reported. Finally, the two different methodologies are compared. 


\subsection{Personality evaluation methodology 1: Aaker's personality traits}

From Methodology 1, an important finding is the selection of attributes that best represents the personality of the current VAVA's in the market. In general, the attributes most frequently associated with them by the total sample are: Practical, Informed, Up-to-Date, Well-Mannered, Logical and Helpful.

Figure 1 shows that these attributes do no differ significantly when split by each VAVA. What does change among them is the order of the ranking. For instance, Siri users selected as the first characterizing attribute Well-Mannered, while for Google it is Practicality, for Alexa it is being Helpful, and for Cortana it is being Informed. Each of these attributes appear among the most selected for all VAVAs, with the only difference being the ranking order. What draws attention is that in a list of 29 different personality attributes, these four VAVAs share the same ones. When it comes to differences highlighted in this analysis, it is worth considering that Alexa users attribute to this VAVA the trait of Kind, which no other VAVA got as a top representative trait.

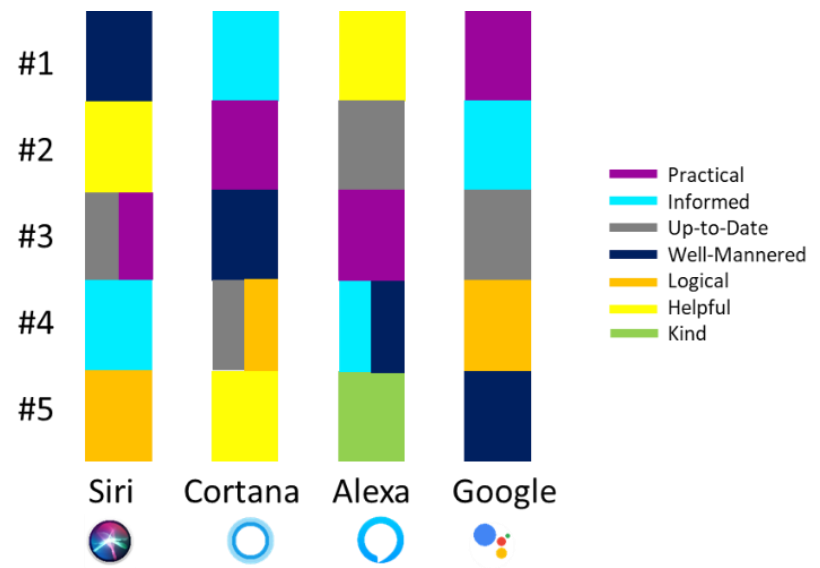

Figure 1: Ranking of most chosen attributes to describe current VAVAs

Furthermore, if these are the most chosen attributes, it is also relevant to highlight those ones that were the least chosen to represent their current VAVA's personality, regardless of the profile responding: Cheerful, Sweet, Sentimental and Masculine.

A second stage of this quantitative study, using Methodology 1, was to identify the most indispensable attributes VAVAs should have. Users were asked to choose from the same list of 29 Aaker traits, which ones would they wish to have in their VAVA. They were then asked to prioritize them until they told us the top three that were essential for the VAVA to have. The analysis of this data revealed the indispensable personality attributes that participants wished for their desired VAVA: Reliable, Informed, Intelligent, Objective, Practical.

As it happened with current personality traits, the variations that can be noticed among VAVAs are shown in Figure 2, which visualizes that differences are slight, similarly to what was noticed with the current traits. Only the order in which users of each VAVA position these five traits change. As in current traits, Alexa needs a special mention, as its users differ from the rest of the group; they chose as an essential attribute in their desired VAVA Helpful instead of Objective like the others' VAVA users.

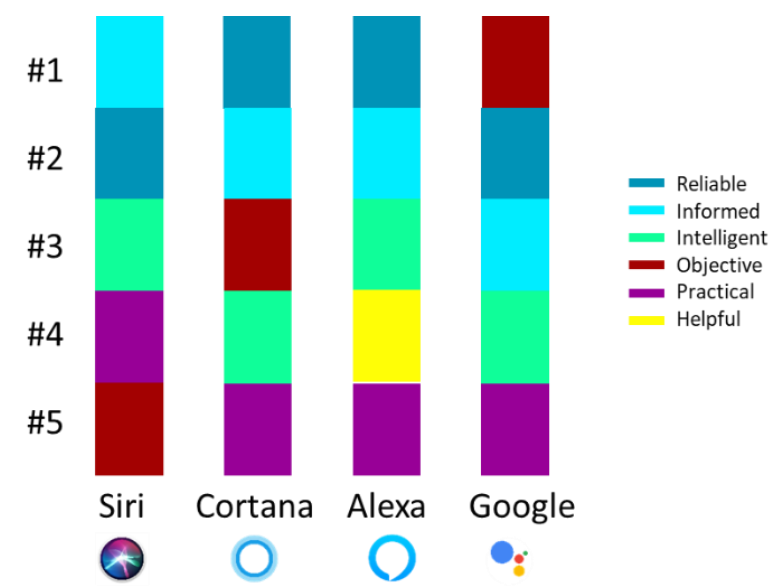

Figure 2: Ranking of Indispensable Attributes by VAVA

The results shown represent global results. However, when splitting the data by country, few cultural differences appear among the characteristics found as essential for a VAVA (Figure 3). In Germany, Spain and UK, as in the general average, Reliable is the most essential attribute. Instead, in Argentina and Chile, this attribute falls to the fifth position and the most indispensable attribute is Informed. Also, in Chile, instead of Practical, the desired VAVA should be Original, while in Brazil users also choose the latter over Informed, and placed it as their most indispensable characteristic for a VAVA. Major differences are observed in Germany and UK as they both add Helpful instead of Objective, and UK adds Honest instead of Practical to the top 5 essentials, although this is only by a small difference.

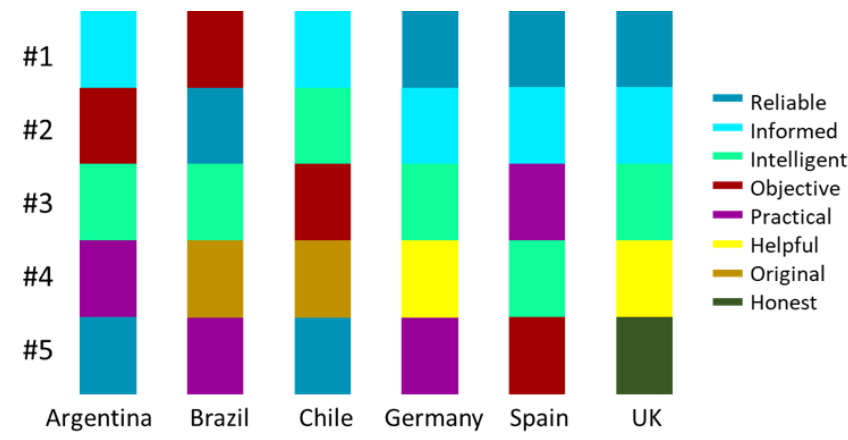

Figure 3: Ranking of Indispensable Attributes by country 


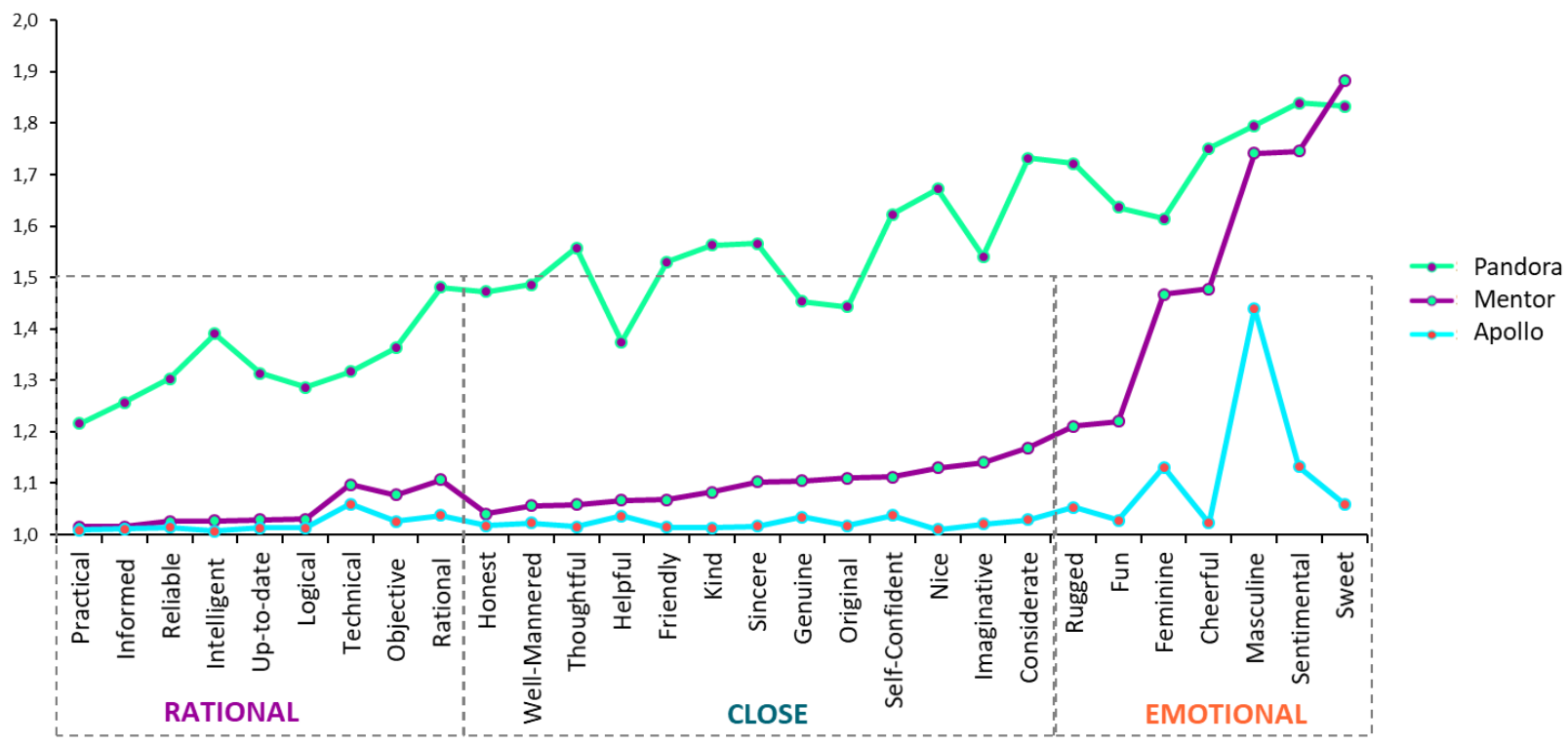

Figure 4: Cluster analysis on desired attributes for a VAVA

A cluster analysis was conducted with the selected attributes for the desired VAVA, to understand if user preferences revealed uniquely different sets of attributes for their desired VAVA. Three clusters emerged according to the attributes chosen for their VAVA, and while reviewing those attributes included in each cluster, logically three factors were created: (i) The first cluster group, named Pandora, wants all possible attributes in their VAVA. They do not disregard any attribute, neither from the rational nor from the emotional factors. (ii) The second cluster group are those users that who like their VAVA to be a Greek mythology's Mentor, wise but close, giving sage advice using rationality but still being agreeable and friendly. (iii) Finally, the third group wants their VA to resemble Greek god Apollo, a rational expert that uses technology to provide logical solutions with rigor and solvency, without empathic features. As it is shown in Figure 4, each cluster includes the characteristics of the rational factor, while the differences reside in the inclusion of more attributes of the emotional spectrum.

Almost all VAVA users (96\%) incorporate in their choice of desired VAVA at least 2/3 of the proposed rational attributes, labeled as "Many" in Figure 5.

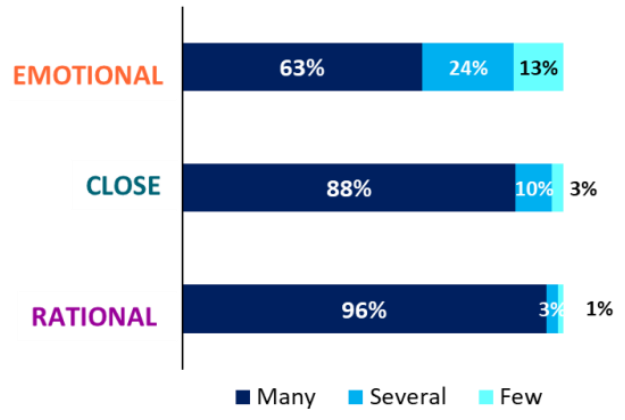

Figure 5. Percentage of sample that selected proportion of attributes by factor
This proportion is reduced with the incorporation of more emotional attributes.

As to cultural variances in this regard, few country differences were found around this aspect. The UK stands out for the low incorporation of emotional attributes, and Brazil stands out at the opposite side of the spectrum with many emotional attributes. While $76 \%$ of VAVA users in Brazil incorporate at least $2 / 3$ of the proposed emotional attributes, only $32 \%$ of them do so in the UK. For the other two factors, Rational and Close, no relevant differences were detected.

When dividing the sample into the different VAVAs, it was noticed that Alexa users chose fewer emotional attributes than the other VAVA's users. It seems they look for a fair number of emotional attributes, not going into any extreme.
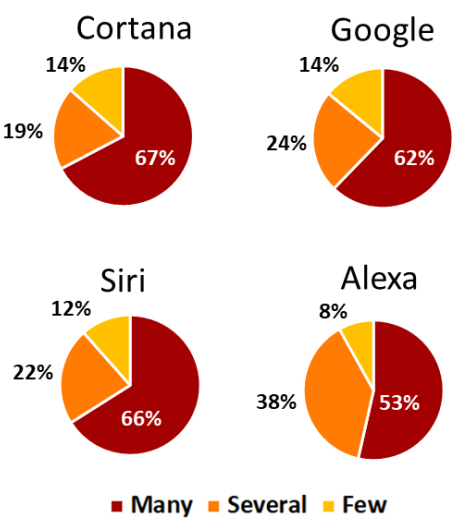

Figure 6. Percentage of sample that selected proportion of emotional attributes by VAVA

Differences between Alexa and other VAVAs have been observed already in other studies (Perez et al., 2018). For instance, Alexa users report using more use cases and a higher frequency of use than other 
VAVA users. It would be possible to hypothesize that this may be having an effect on Alexa's personality, making it different from the other three current VAVAs.

An analysis of the gaps between current and desired personality attributes was carried out shedding light onto a series of findings: (i) Most participants have claimed they want more of the same attributes their VAVAs currently have: Reliable, Intelligent, Objective, Original and Thoughtful. The previous are the atributes where greater gaps were found based on the evaluation of the complete sample. Neverthless, when doing an analysis per VAVA users, some differences emerged. Siri users, as the general sample present its major differences between desired and current in Reliable, Intelligent and Objective, while Cortana users emphasized wanting a Reliable VAVA, and a big gap was identified in Sincere and Rational. The evaluation of Alexa is more adjusted to what its users want because the current and desired top ranking attributes are very similar, therefore they are receiving from their VAVA what they desire from its personality. The only attribute that stands out is Reliable, ranked 10th in the evaluation of the current VAVA, while it is 4th in the ranking of desired attributes. Google users also seem to be very satisfied with the attributes of their VAVA because there are few differences between current and desired VAVA attributes ranking.

\subsection{Personality evaluation methodology 2: Jung's archetypes}

When exploring the current personality based on Jung's archetypes, using the second methodology, some themes emerged. As Figure 2 shows, the four VAVAs have very similar perceived personalities. They all have a high evaluation on the Sage archetype. However, Siri is the one that is mostly characterized as this archetype and it also has a high mark for Innocent, while Alexa scores higher on Jester, Google on Explorer and Cortana on Creator.

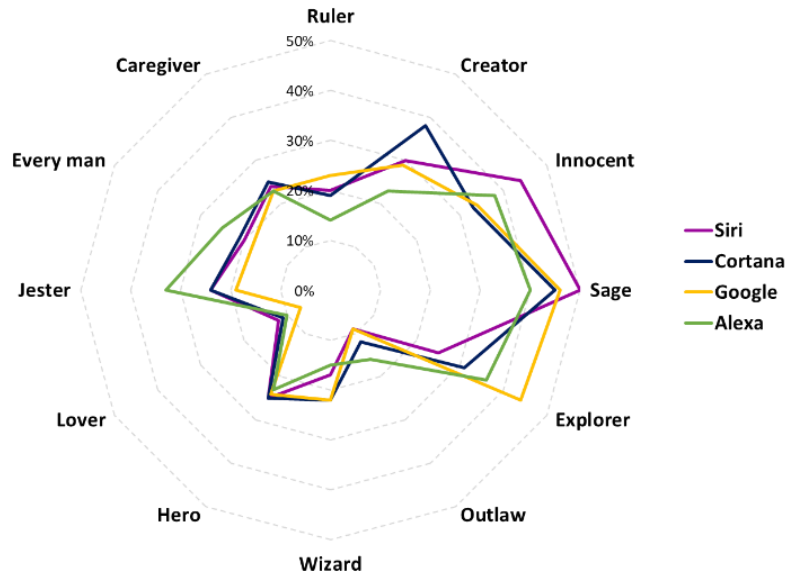

Figure 7: Personality Archetypes for current VAVAs
Regarding their desired VAVA, an interesting observation was that no matter the current VAVA users were using, their most desired archetype was unanimously the Sage. However, it is important to highlight the difference among another highly indispensable archetype choice for Alexa's users, the Explorer, which differed from the other VAVA users. Once more, Alexa users' answers generate questions about how the experience of this VAVA is changing the perception of desired personality for the category.

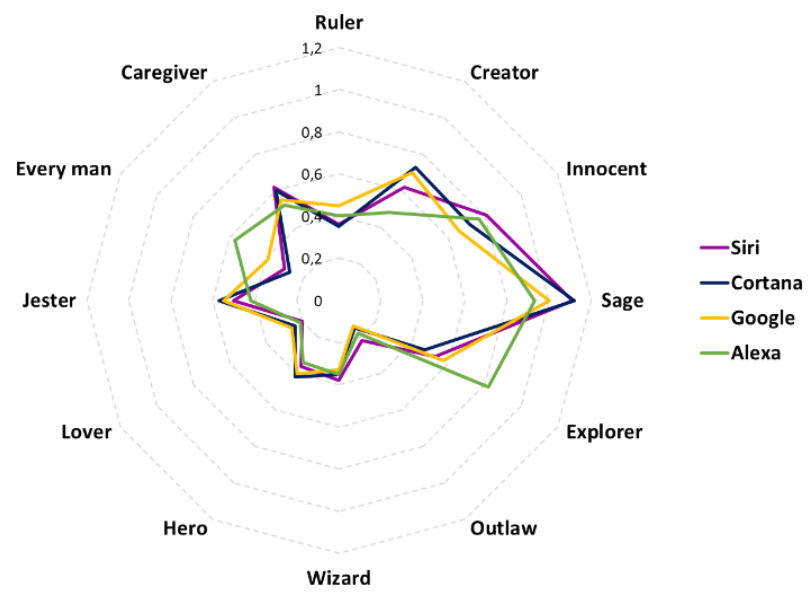

Figure 8: Summary of averages from archetypes chosen as indispensable, divided by VAVA most frequently used

\subsection{Blending results from the two personality evaluation methodologies}

Once the results were analyzed separately, the objective of the study was also to cross-analyze the data of both methodologies to identify if results were similar, or if some differences arose between the attributes and archetypes chosen. The relationship and comparison between the two methodologies is an interpretation of the research team, therefore subjective.

Firstly, the fact that the personalities between the four VAVA's had so few differences in the general view of the attributes and archetypes for the current VAVAs, was a first indication that a relationship may exist between the two methodologies. The Sage, as the most prominent archetype in all VAVAs, connects to attributes most chosen for the VAVA's current personality sample such as Practical, Informed and Logical. However, other attributes that could be associated to the Sage archetype, such as Intelligent, Rational and Objective were not in the most chosen traits. At the other end of the spectrum, the least chosen attributes for the VAVAs, like Sweet and Sentimental, could also be linked and endorsed to the least chosen archetype, the Lover.

Secondly, when splitting results into the different VAVAs some aspects have also drawn our attention. 
Siri, for example, is the VAVA that stands out as the closest to the Sage and Innocent archetypes, yet the attributes chosen by its users are Well-Mannered and Helpful, which stray from the core traits of the previous mentioned archetypes. For Cortana, a similar case occurs, as Figure 6 shows, when it is linked to the Creator archetype, although more Sage-like attributes are at the top of its user's list, for instance Informed and Practical. In the case of Alexa, a relationship between both methodologies can be appreciated. In comparison with the other VAVA's, Alexa has the least selection of the Sage archetype, even though is still the most chosen. When reviewing the attributes selected, it is the only VAVA which does not include Logical in its top selection, while Informed drops down to $4^{\text {th }}$ compared to $1^{\text {st }}$ and $2^{\text {nd }}$ position in Cortana and Google. Nonetheless, the most chosen trait, Helpful, and the one Alexa has than none of the others do, Kind, are not characteristics included in the various descriptions of the Jester, where Alexa stands out from the rest of the VAVAs. Lastly, Google peaks on the Explorer archetype and, even though by very few, surpasses the other VAVAs in Ruler. This could be related to its top traits Practical and Informed.

When comparing the attributes chosen as indispensable and the archetypes that described the desired VAVA, the two methodologies seem to converge on similar results. Once again, the Sage was the most selected archetype by the complete sample, which relates closely to all of the top five attributes selected as indispensables for the desired VAVA: Reliable, Informed, Intelligent, Objective, and Practical.

Additionally, as it happened with the attributes methodology, in the archetype methodology the differences between VAVAs varied much less than in the current personality perception. In a more detailed view of each VAVA, other aspects strengthen the linkage between the two methodologies. For example, Siri's users, as with the current personality, chose Sage as its more prominent archetype, which can be linked to all of the top five attributes chosen. This shift of Sage-like attributes could also be related to the fact that, differently from their current personality choice, the Innocent archetype was less selected as a desired archetype. Alexa's respondents, in both methodologies, show a connection between attributes and archetypes. They included an attribute that is part of the Close factor, such as friendly or amiable, in the top 5 indispensable, which may be linked to other Alexa users that chose less Sage as the desired personality and more Explorer and Every Man's archetype, compared the other VAVA users.

\section{CONCLUSIONS}

People are used to interacting with technology and expect it to perform well. However, as time passes and VAVA adoption is escalating in society, it becomes more important for organizations to start considering that their VAVAs are not just neutral technologies. Precisely because they use a type of interaction, voice, that is only related to human beings, emotional connections start to arise. This study was aimed at exploring people's perceptions around personality of VAVAs from two different personality evaluation perspectives, and the methodology of this study has helped to identify a series of learnings and considerations. Firstly, this study has demonstrated that brand focused personality evaluation frameworks, such as Aaker's and Jung's, are perfectly suitable to evaluate artificial intelligence applications such as VAVAs. Secondly, it has also shown that, no matter the framework used, results appear rather similar, which strengthens the idea that, when interacting with technology, personality traits always come across rather clearly to the user. Consequently, this study has demonstrated that it is not only important to perform well but to transmit a suitable personality that meets users' needs and desires both for the present and the future.

\section{FURTHER RESEARCH}

This research study has suggested potential applications of personality perceptions and desires in general voice activated virtual assistants so it becomes of interest to explore its application in more complex interactions, such as what should the behavioral change for emotional health and wellbeing.

This research study is crucial for developing a future suitable systems design that can meet users requirements not only for the UX but also for marketing, design, cognitive, product and delivery point of view.

\section{REFERENCES}

Aaker, J. (1997) Dimensions of Brand Personality. Journal of Marketing Research, 34(3), 347-356.

Aaker, J., Benet-Martinez, V. and Gorolera, J. (2001) Consumption symbols as carriers of culture: A study of Japanese and Spanish brand personality constructs. Journal of Personality and Social Psychology, 81(3), 492-508.

Ball, G. and Breeze, J. (2000) Emotion and personality in a conversational agent. In Cassell, J., Sullivan, J., Prevost, S. and Churchill, E. (eds.), Embodied Conversational Agents. MIT Press, Cambridge, Massachusetts.

Barrios, M. and Massa, C. (1999) Dimensiones de la personalidad de marca en Venezuela (Master Thesis). Instituto de Estudios Superiores de Administración, Caracas, Venezuela. 
Bechter, C., Farinelli, G., Daniel, R. D. and Frey, M. (2016) Advertising between archetype and brand personality. Administrative Sciences, 6(2), 5.

Bolhuis, S. (2011) Archetypen: onderzoek naar de visualisatie (Master's Thesis). University of Twente, Enschede, Netherlands.

Cohen, M.H., Giangola, J.P. and Balogh, J. (2004) Voice User Interface Design. Addison-Wesley Professional, Boston, Massachusetts.

Durgee, J.F. (1988) Interpreting Consumer Mythology: a Literary Criticism Approach to Odyssey Informant Stories. In Houston, M.J. (Ed.), Advances in Consumer Research. Association for Consumer Research, Provo, Utah.

Eadiccio, L. (2017) Google Wants to Give Your Computer a Personality. http://time.com/4979262/google-wants-to-givecomputer-personality/ (201/02/20).

Ekinci, Y. and Hosany, S. (2006) Destination Personality: An Application of Brand Personality to Tourism Destinations. Journal of Travel Research, 45, 127-139.

Ekinci, Y. and Riley, M. (2003) An investigation of self-concept: actual and ideal self-congruence compared in the context of service evaluation. Journal of Retailing and Consumer Services 10, 201-214.

Faber, M. and Mayer, J. (2009) Resonance to archetypes in media: There's some accounting for taste. Journal of Research in Personality, 43(3), 307-322.

First, I. and Grbac, B. (2007) Brand Preference: Effects of Country of Origin and Brand's Personality Traits. Thought Leaders International Conference on Brand Management, Birmingham, UK, April 24-25 2007.

Funder, D.C. (2001) The Personality Puzzle. Norton, New York, New York.

Hoolwerff, D. (2014) Does your mascot match your brand's personality? An empirical study on how visual characteristics of a brand mascot can function as a tool for transmitting an archetypical brand personality (Master's Thesis), University of Twente, Enschede, Netherlands.

Jansen, M. (2006) Brand Prototyping: Developing meaningful brands. Kluwer.

Johnson, K. (2017) People, not tech companies, should pick their $\mathrm{Al}$ assistant's personality. https://venturebeat.com/2017/10/02/tech-giantsshould-let-people-pick-their-ai-assistantspersonality/ (2018/02/28).

Jung, C.G. (1954) Psychological Aspects of The Mother Archetype. In Read, H., Fordham, M., and Adler, G. (Eds.), The Collected Works of C. G. Jung. Routledge, London, UK.
Klarquist, D. (2010) Added Value CharacterLab ${ }^{\mathrm{TM}}$ Archetypes Go Live at ARF, Press Release. http://www.wpp.com/wpp/press/2010/mar/02/ad ded-value-characterlab-archetypes-go-live-at/ (2018/02/26).

Koebel, M. and Ladwein, R. (1999) L'échelle de personnalité de la marque de Jennifer Aaker: Adaptation au contexte français. Decisions Marketing, 18, 81-88.

Li, J., Galley, M., Brockett, C., Spithourakis, G.P., Gao, J. and Dolan, B. (2016) A Persona-Based Neural Conversation Model. arXiv preprint arXiv:1603.06155. https://arxiv.org/pdf/1603.06155.pdf (2018/03/08)

Mairesse, F., and Walker, M. (2007) PERSONAGE: Personality generation for dialogue. 45th Annual Meeting of the Association of Computational Linguistics, Prague, Czech Republic, June 2330 2007, 496-503.

Mark, M., and Pearson, C. (2001) The Hero and the Outlaw: Building Extraordinary Brands Through The Power Of Archetypes. McGrawHill.

Mayer, J.D. (2007) Asserting the definition of personality. The online newsletter for personality science, 1, 1-4.

McKay, E. (2017) Delightful user experience: How to design Uls that are polite and forgiving, and have a great personality. Conference Interaction South America, Floripa, Brazil, November 9-11 2017.

Moffat, D. (1997) Personality parameters and programs. In Trappl, R. and Petta, P. (eds.), Creating personalities for synthetic actors. Springer, Berlin, Germany.

Mori, M. (1970) The Uncanny Valley. Energy, 7(4), 33-35.

Munteanu, A., Costea, I., Palos, R., and Jinaru, A. (2010) Entering in the essences of personalitystudies over archetypes. Procedia-Social and Behavioral Sciences, 5, 2272-2276.

Neff, M., Wang, Y., Abbott, R., and Walker, M. (2010) Evaluating the effect of gesture and language on personality perception in conversational agents. International Conference on Intelligent Virtual Agents, Philadelphia, Pennsylvania, September 20-22 2010, 222-235. Springer, Berlin, Germany.

Ovarrieta, S., Friedman, R. and Manzur, E. (2010) Brand personality in Chile: a combined emicepic approach. Estudios de Administración, 17(1), 25-50.

Perez, M. and Saffon, S. (2018) Building trust between Users and Data Driven Virtual Assistants. 14th International Conference on Artificial Intelligence Applications and Innovations, Rhodes, Greece, May 25-27 2018. 
Perez, M., Saffon, S. and Donis, H. (2018) Everybody is talking about Voice Activated Virtual Assistants, but how are people really adopting and using them? Lessons from a multicountry study. Under review for the 32nd Human Computer Interaction Conference, Belfast, Northern Ireland, 2-6 July 2018.

Pearson, C. S., and Marr, H. K. (2002) PearsonMarr Archetype Indicator. Center for Applications of Psychological Type, Gainesville, Florida.

Pirela, J. L., Villavicencio, H. and Saavedra, J. L. (2004) Dimensiones de personalidad de marca: estudio exploratorio de los rasgos de personalidad en Venezuela. Revista de Ciencias Sociales, 10 (3), 430-440.

Plummer, J.T. (1985) How Personality Makes a Difference. Journal of Advertising Research, 24, 27-31.

Reilly, W. (1996) Believable Social and Emotional Agents (PhD Thesis). School of Computer Science, Carnegie Mellon University, Pittsburgh, Pennsylvania.

Roberts, C. (2010) Exploring brand personality through archetypes. Doctoral dissertation, East Tennessee State University, Johnson City, Tennessee.

Schlesinger, W., and Cervera, A. (2009) Naturaleza y dimensionalidad de la personalidad de marca en el ámbito de los servicios. Técnica administrativa, 8, 39.

Short, T.X. (2017) Designing Stronger Al Personalities. 13th Artificial Intelligence and Interactive Digital Entertainment Conference. Little Cottonwood Canyon, Utah, October 5-9 2017.

Stanford University (2018) Personality and Voice in Al. Creating Al Conversations Panel Series, Stanford, California, January 242018.

Sung, Y. and Tinkham, S. (2005) Brand Personality Structures in the United Status and Korea: Common and Culture-Specific Factors, Journal of Consumer Psychology, 15(4) 334-350.

Suppehellen, M. and Gornhaug, K. (2003) Building foreign brand personalities in Russia: the moderating effect of consumer ethnocentrism. International Journal of Advertising, 22(2), 203226.

Weigner, I.B. and Green, R.L. (2017) Handbook of Personality Assessment. Wiley \& Sons, Hoboken, New Jersey.

Woodside, A.G., Sood, S., and Miller, K.E. (2008) When consumers and brands talk: Storytelling theory and research in psychology and marketing. Psychology and Marketing, 25(2), 97-145. 